\title{
Sistem Pendukung Keputusan Prioritas Calon Penerima Bantuan Program Indonesia Pintar (PIP) pada Siswa Tingkat Sekolah Dasar Menggunakan Metode Moora
}

\author{
Laurensia Agustin Manik $^{1}$, Yani Maulita ${ }^{2}$, Indah Ambarita ${ }^{3}$ \\ ${ }^{1,2,3}$ STMIK Kaputama Binjai, Indonesia
}

\begin{tabular}{l} 
ARTICLE INFORMATION \\
\hline Received: Maret, 20, 2021 \\
Revised: Maret 26, 2021 \\
Available online: April,28,2021 \\
KEYWORDS \\
\hline PIP_Assistance, MOORA, Decision Support \\
System \\
CORRESPONDENCE \\
\hline Phone: +62 (0751) 12345678 \\
E-mail: laurensiamanik16@gmail.com
\end{tabular}

\begin{abstract}
A B S T R A C T
Regarding assistance from the recipients of the Smart Indonesia Program (PIP) because there are so many prospective recipients of PIP assistance who volunteered to get the assistance, the process of delivering aid is sometimes not on target. Invalid data causes errors in the distribution of PIPs given to recipients who are entitled to receive them Special Decision Support System (SPK) was built to support the solution of a problem or for an opportunity, one of the PIP aid recipient's approval in the Binjai City Education Office so that it is right on target for students who will get PIP assistance. The role of decision support systems is needed to improve the efficiency of decision making in determining students who are eligible for PIP assistance. The method used in this system uses the Multi-Objective Optimization method on the basis of Ratio Analysis (MOORA) and by using 7 (seven) criteria, namely family conditions, report card scores, parental work, number of dependents, number of dependents of children who attend school, home conditions and parents' income as well as 10 (ten) alternatives that are student data. Based on the results of calculations using the MOORA method, students on behalf of MM (A9) are the best alternative to be given PIP assistance with a value of 0.2843
\end{abstract}

\section{PENDAHULUAN}

Dinas Pendidikan Kota Binjai merupakan instansi pemerintah yang bertanggungjawab tentang semua hal yang berkaitan dengan pendidikan di Kota Binjai. Dinas Pendidikan ini juga menjadi pembina dan pemberi izin sekolah dari taman kanak-kanak, sekolah dasar, sekolah menengah pertama, sekolah menengah atas, hingga lembaga bimbingan belajar. Secara umum, dinas pendidikan dan pengajaran berdiri atas keputusan pemerintah yang ditugaskan untuk menangani pelayanan dibidang pendidikan dan pengajaran. Dinas pendidikan berfungsi sebagai tempat mengkoordinasi, mengelola dan mengembangkan sistem pendidikan di Indonesia[1]. Tingkat pendidikan di Indonesia masih tergolong sangat rendah. Karena masih banyak anak-anak di Indonesia yang putus sekolah. Salah satu cara mengatasi masalah pendidikan di Indonesia yaitu dengan adanya Program Indonesia Pintar (PIP). Pemerintah mengeluarkan bantuan program pendidikan berupa Program Indonesia Pintar (PIP) melalui Kartu Indonesia Pintar (KIP).

Di kota Binjai juga masih terdapat anak yang putus sekolah maupun yang tidak sekolah namun masih belum mendapatkan bantuan PIP. Dalam pendataan calon penerima bantuan PIP di Dinas Pendidikan Kota Binjai masih menggunakan proses manual untuk pengambilan keputusan prioritas penerima bantuan PIP, hal ini berakibat pada proses pemberian bantuan tersebut yang tidak tepat sasaran pada siswa yang seharusnya membutuhkan bantuan PIP. Terdapat kesalahpahaman orangtua dan ketidakadilan sekolah dikarenakan ada siswa yang tidak mendapatkan bantuan PIP yang seharusnya siswa tersebut layak mendapatkan bantuan dibandingkan dengan siswa lain yang sebenarnya mampu tetapi mendapatkan bantuan tersebut. Oleh karena itu terjadi kesalahan yang menyebabkan salah sasaran terutama di sekolah yang terkendala dengan banyaknya kriteria yang harus diperhitungkan sehingga kesulitan dalam menentukan prioritas calon penerima bantuan PIP .

Bantuan PIP membantu meringankan biaya personal pendidikan, mencegah agar siswa tidak putus sekolah serta mendorong siswa putus sekolah dan tidak sekolah agar dapat melanjutkan pendidikannya. Di tahun 2019 terdapat sebanyak 179 siswa yang putus sekolah pada tingkat SD di Kota Binjai [2]. Syarat untuk mendapatkan PIP harus mendaftar ke Dinas Pendidikan dengan membawa Kartu Keluarga Sejahtera (KKS) atau Surat Keterangan Tidak Mampu (SKTM). Siswa/anak dari keluarga pemegang KKS dan yatim piatu akan menjadi sasaran utama dalam mendapatkan bantuan PIP tersebut.

Untuk mengatasi hal itu, maka diperlukan sebuah sistem yang dapat menyeleksi berdasarkan kriteria yang telah ditetapkan dalam memberikan prioritas penerima bantuan PIP kepada anak sekolah yang layak mendapatkan bantuan tersebut. Sistem pendukung keputusan merupakan salah satu produk perangkat lunak yang dikembangkan secara khusus untuk membantu dalam proses pengambilan keputusan khususnya dalam pengambilan keputusan prioritas calon penerima bantuan PIP dengan menggunakan metode Multi-Objective Optimization on the basis of Ratio Analysis (MOORA)

Sistem Pendukung Keputusan Prioritas Calon Penerima Bantuan Program Indonesia Pintar (PIP) pada Siswa Tingkat Sekolah Dasar Menggunakan Metode Moora. Oleh : Laurensia Agustin Manik, Yani Maulita, Indah Ambarita 


\section{BAHAN DAN METODE}

\subsection{Sistem Pendukung Keputusan}

Sistem Pendukung Keputusan (SPK) atau Decision Support System (DSS) adalah "sistem informasi interaktif yang menyediakan informasi, pemodelan, dan pemanipulasian data yang digunakan untuk membantu pengambilan keputusan dalam situasi yang semi terstruktur dan situasi yang tidak terstruktur, dimana tak seorang pun tahu secara pasti bagaimana keputusan seharusnya dibuat"[3], [4]. SPK ditujukan untuk mendukung manajemen dalam melakukan pekerjaan yang bersifat analitis dalam situasi yang kurang terstruktur dengan kriteria yang kurang jelas. DSS tidak dimaksudkan untuk mengotomatiskan pengambilan keputusan, tetapi memberikan perangkat interaktif yang memungkinkan pengambil keputusan untuk melakukan berbagai analisis menggunakan modelmodel yang tersedia. Keputusan merupakan kegiatan memilih suatu strategi atau tindakan dalam pemecahan masalah[5].

\subsection{Program Indonesia Pintar}

Secara umum Program Indonesia Pintar adalah progam bantuan dari pemerintah kepada anak usia sekolah yang orang tuanya kurang mampu untuk diberikan bantuan uang tunai ditandai dengan adanya Kartu Indonesia Pintar. Program Indonesia Pintar (PIP) adalah salah satu program nasional yang bertujuan untuk meningkatkan angka partisipasi pendidikan dasar dan menengah, meningkatkan angka berkelanjutan pendidikan, menurunkan kesenjangan partisipasi pendidikan, meningkatkan kesiapan siswa pendidikan menengah untuk menghadapi pasar kerja [6].

PIP mulai tahun 2015 berdasarkan Permendikbud Nomor 12 Tahun 2015 tentang Program Indonesia Pintar, yang mana Permendikbud ini ditetapkan dan mulai diundangkan pada tanggal 12 Mei 2015. PIP diselenggarakan dalam rangka melaksanakan ketentuan Instruksi Presiden Nomor 7 Tahun 2014 tentang Pelaksanaan Program Simpanan Keluarga Sejahtera, Program Indonesia Pintar dan Program Indonesia Sehat untuk membangun keluarga produktif.

\subsection{Metode MOORA}

Metode Multi-Objective Optimization on the basis of Ratio Analysis (MOORA) adalah multiobjektif sistem mengoptimalkan dua atau lebih attribut yang saling bertentangan secara bersamaan. Metode ini diterapkan untuk memecahkan masalah dengan perhitungan matematika yang kompleks [7], [8].

Menurut penelitian tentang penerapan metode Multi-Objective Optimization on the basis of Ratio Analysis (MOORA) dalam sistem pendukung keputusan penentuan kadar minyak mentah oleh Ginting, Agung (2020), diperoleh prosedur dalam metode MOORA terdiri dari beberapa tahap yaitu:

Pembentukan matriks, dengan menggunakan rumus:

1. Pembentukan matriks, dengan menggunakan rumus [9]:

$$
x=\left[\begin{array}{ccccc}
x_{11} & \cdots & x_{12} & \cdots & x_{1 n} \\
\vdots & \ddots & \vdots & \ddots & \vdots \\
x_{21} & \cdots & x_{22} & \cdots & x_{2 n} \\
\vdots & \ddots & \vdots & \ddots & \vdots \\
x_{m 1} & \cdots & x_{m 2} & \cdots & x_{m n}
\end{array}\right]
$$

2. Menentukan matriks normalisasi, dengan rumus :

$$
\begin{aligned}
& y_{i}=\sum_{j=1}^{g} W_{j} X_{i j}-\sum_{j=g+1}^{n} W_{j} X_{i j} \\
& x_{i j}=\frac{x_{i j}}{\sqrt{\sum_{j=1}^{m} x_{i j}^{2}}}
\end{aligned}
$$

3. Menentukan nilai preferensi, dengan menggunakan rumus :

$$
y_{i}=\sum_{j=1}^{g} w_{j} x_{i j}^{*}-\sum_{j=g+1}^{n} w_{j} x_{i j}^{*}
$$

\section{HASIL DAN PEMBAHASAN}

Proses yang dilakukan pada Metode Multi-Objective Optimization on the basis of Ratio Analysis (MOORA) memerlukan kriteria-kriteria dalam perhitungan yang akan dilakukan. Kriteria-kriteria tersebut dapat dilihat pada tabel berikut:

Tabel 1 Kriteria

\begin{tabular}{|l|l|l|l|}
\hline Kriteria & Nama Kriteria & Bobot & Jenis \\
\hline C1 & Kondisi Keluarga & 0,18 & Benefit \\
\hline C2 & Nilai Raport & 0,05 & Benefit \\
\hline C3 & Pekerjaan Orang Tua & 0,15 & Benefit \\
\hline C4 & Jumlah Tanggungan Anak & 0,2 & Benefit \\
\hline C5 & Jumlah Tanggungan Anak yang Sekolah & 0,12 & Benefit \\
\hline C6 & Kondisi Rumah & 0,16 & Benefit \\
\hline C7 & Penghasilan Orang Tua & 0,14 & Cost \\
\hline
\end{tabular}

Untuk setiap kriteria memiliki masing-masing sub kriteria dan bobot. Berikut ini merupakan sub kriteria dari masing-masing kriteria. Tabel 2 merupakan tabel yang berisikan kriteria kondisi keluarga yaitu sebagai berikut:

Sistem Pendukung Keputusan Prioritas Calon Penerima Bantuan Program Indonesia Pintar (PIP) pada Siswa Tingkat 
Tabel 2 Kondisi Keluarga

\begin{tabular}{|l|l|l|}
\hline Kondisi Keluarga & Keterangan & Bobot \\
\hline Yatim & Cukup & 1 \\
\hline Piatu & Baik & 2 \\
\hline Yatim Piatu & Sangat Baik & 3 \\
\hline
\end{tabular}

Tabel 3 merupakan tabel yang berisikan kriteria nilai raport untuk semester terakhir di kelas 5 yaitu sebagai berikut:

Tabel 3 Nilai Raport

\begin{tabular}{|l|l|l|}
\hline Nilai Raport & Keterangan & Bobot \\
\hline$\leq 70$ & Tidak Baik & 1 \\
\hline $71-80$ & Cukup & 2 \\
\hline $81-90$ & Baik & 3 \\
\hline $91-100$ & Sangat Baik & 4 \\
\hline
\end{tabular}

Tabel 4 merupakan tabel yang berisikan kriteria pekerjaan orang tua yaitu sebagai berikut:

Tabel 4 Pekerjaan Orang Tua

\begin{tabular}{|l|l|l|}
\hline Pekerjaan Orang Tua & Keterangan & Bobot \\
\hline Karyawan & Tidak Baik & 1 \\
\hline Petani & Cukup & 2 \\
\hline Serabutan & Baik & 3 \\
\hline Tidak Bekerja & Sangat Baik & 4 \\
\hline
\end{tabular}

Tabel 5 merupakan tabel yang berisikan kriteria jumlah tanggungan anak yaitu sebagai berikut:

Tabel 5 Jumlah Tanggungan Anak

\begin{tabular}{|l|l|l|}
\hline Jumlah Tanggungan Anak & Keterangan & Bobot \\
\hline 1 Tanggungan & Tidak Baik & 1 \\
\hline 2 - 3 Tanggungan & Cukup & 2 \\
\hline 4-5 Tanggungan & Baik & 3 \\
\hline$>$ 6 Tanggungan & Sangat Baik & 4 \\
\hline
\end{tabular}

Tabel 6 merupakan tabel yang berisikan kriteria jumlah tanggungan anak yang sekolah yaitu sebagai berikut:

Tabel 6 Jumlah Tanggungan Anak yang Sekolah

\begin{tabular}{|l|l|l|}
\hline Jumlah Tanggungan Anak yang Sekolah & Keterangan & Bobot \\
\hline 1 Tanggungan & Tidak Baik & 1 \\
\hline 2 - 3 Tanggungan & Cukup & 2 \\
\hline 4-5 Tanggungan & Baik & 3 \\
\hline$>6$ Tanggungan & Sangat Baik & 4 \\
\hline
\end{tabular}

Tabel 7 merupakan tabel yang berisikan kriteria kondisi rumah yaitu sebagai berikut:

Tabel 7 Kondisi Rumah

\begin{tabular}{|l|l|l|}
\hline Kondisi Rumah & Keterangan & Bobot \\
\hline Batu Separuh & Cukup & 1 \\
\hline Papan & Baik & 2 \\
\hline Tepas & Sangat Baik & 3 \\
\hline
\end{tabular}

Tabel 8 merupakan tabel yang berisikan kriteria penghasilan orang tua yaitu sebagai berikut:

Tabel 8 Penghasilan Orang Tua

\begin{tabular}{|l|l|l|}
\hline Penghasilan Orang Tua & Keterangan & Bobot \\
\hline > Rp.1.500.000 & Tidak Baik & 1 \\
\hline Rp.1.000.000 - Rp.1.499.999 & Kurang Baik & 2 \\
\hline Rp.700.000 - Rp.999.999 & Cukup & 3 \\
\hline < Rp.699.999 & Baik & 4 \\
\hline Tidak Ada Penghasilan & Sangat Baik & 5 \\
\hline
\end{tabular}


Berikut ini adalah data calon penerima bantuan PIP, yaitu sebagai berikut:

Tabel 9 Data Siswa Yang Menjadi Alternatif

\begin{tabular}{|l|c|c|c|c|c|c|c|c|}
\hline & & & & & & \\
\hline A1 & AR & Yatim & 85 & Petani & 3 & 3 & Papan & 600.000 \\
\hline A2 & Sas & Yatim & 85 & Serabutan & 3 & 2 & Tepas & 400.000 \\
\hline A3 & AH & Yatim & 88 & Petani & 2 & 2 & Papan & 500.000 \\
\hline A4 & IR & $\begin{array}{c}\text { Yatim } \\
\text { Piatu }\end{array}$ & 90 & $\begin{array}{c}\text { Tidak } \\
\text { Bekerja }\end{array}$ & 1 & 1 & Tepas & $\begin{array}{c}\text { Tidak Ada } \\
\text { Penghasilan }\end{array}$ \\
\hline A5 & MY & Yatim & 80 & Petani & 5 & 3 & $\begin{array}{c}\text { Batu } \\
\text { Separuh }\end{array}$ & 900.000 \\
\hline A6 & DP & Yatim & 85 & Serabutan & 2 & 1 & Tepas & 300.000 \\
\hline A7 & RA & Piatu & 80 & Karyawan & 4 & 3 & $\begin{array}{c}\text { Batu } \\
\text { Separuh }\end{array}$ & 1.500 .000 \\
\hline A8 & AU & $\begin{array}{c}\text { Yatim } \\
\text { Piatu }\end{array}$ & 88 & $\begin{array}{c}\text { Tidak } \\
\text { Bekerja }\end{array}$ & 2 & 1 & Tepas & $\begin{array}{c}\text { Tidak Ada } \\
\text { Penghasilan }\end{array}$ \\
\hline A9 & MM & $\begin{array}{c}\text { Yatim } \\
\text { Piatu }\end{array}$ & 92 & $\begin{array}{c}\text { Tidak } \\
\text { Bekerja }\end{array}$ & 3 & 2 & Tepas & $\begin{array}{c}\text { Tidak Ada } \\
\text { Penghasilan }\end{array}$ \\
\hline A10 & MR & Yatim & 80 & Serabutan & 2 & 2 & Papan & 400.000 \\
\hline
\end{tabular}

Berikut ini rating kecocokan alternatif dengan kriteria yang ada, yaitu sebagai berikut:

Tabel 10 Rating Kecocokan Bobot Kriteria

\begin{tabular}{|l|l|l|l|l|l|l|l|}
\hline Alternatif & C1 & C2 & C3 & C4 & C5 & C6 & C7 \\
\hline A1 & 1 & 3 & 2 & 2 & 2 & 2 & 4 \\
\hline A2 & 1 & 3 & 3 & 2 & 2 & 3 & 4 \\
\hline A3 & 1 & 3 & 2 & 2 & 2 & 2 & 4 \\
\hline A4 & 3 & 3 & 4 & 1 & 1 & 3 & 5 \\
\hline A5 & 1 & 2 & 2 & 3 & 2 & 1 & 3 \\
\hline A6 & 1 & 3 & 3 & 2 & 1 & 3 & 4 \\
\hline A7 & 2 & 2 & 1 & 3 & 2 & 1 & 1 \\
\hline A8 & 3 & 3 & 4 & 2 & 1 & 3 & 5 \\
\hline A9 & 3 & 4 & 4 & 2 & 2 & 3 & 5 \\
\hline A10 & 1 & 2 & 3 & 2 & 2 & 2 & 4 \\
\hline
\end{tabular}

1. Langkah awal melakukan persiapan terhadap nilai matrik keputusan $\mathrm{x}$, yang diambil dari tabel 10 .

$$
\mathrm{x}=\left[\begin{array}{lllllll}
1 & 3 & 2 & 2 & 2 & 2 & 4 \\
1 & 3 & 3 & 2 & 2 & 3 & 4 \\
1 & 3 & 2 & 2 & 2 & 2 & 4 \\
3 & 3 & 4 & 1 & 1 & 3 & 5 \\
1 & 2 & 2 & 3 & 2 & 1 & 3 \\
1 & 3 & 3 & 2 & 1 & 3 & 4 \\
2 & 2 & 1 & 3 & 2 & 1 & 1 \\
3 & 3 & 4 & 2 & 1 & 3 & 5 \\
3 & 4 & 4 & 2 & 2 & 3 & 5 \\
1 & 2 & 3 & 2 & 2 & 2 & 4
\end{array}\right]
$$

2. Kemudian melakukan normalisasi matriks $X$.

$$
\begin{aligned}
& \mathrm{C} 1=\sqrt{1^{2}+1^{2}+1^{2}+3^{2}+1^{2}+} \\
& =\sqrt{1^{2}+2^{2}+3^{2}+3^{2}+1^{2}} \\
& =\sqrt{37}=6,0828 \\
& A_{1.1}=\frac{1}{6,0828}=0,1644 \\
& A_{2.1}=\frac{1}{6,0828}=0,1644 \\
& A_{3.1}=\frac{1}{6,0828}=0,1644 \\
& A_{4.1}=\frac{3}{6,0828}=0,4932 \\
& A_{5.1}=\frac{1}{6,0828}=0,1644 \\
& A_{6.1}=\frac{1}{6,0828}=0,1644
\end{aligned}
$$

Sistem Pendukung Keputusan Prioritas Calon Penerima Bantuan Program Indonesia Pintar (PIP) pada Siswa Tingkat Sekolah Dasar Menggunakan Metode Moora. Oleh : Laurensia Agustin Manik, Yani Maulita, Indah Ambarita 


$$
\begin{aligned}
& A_{7.1}=\frac{2}{6,0828}=0,3288 \\
& A_{8.1}=\frac{3}{6,0828}=0,4932 \\
& A_{9.1}=\frac{3}{6,0828}=0,4932 \\
& A_{10.1}=\frac{1}{6,0828}=0,1644
\end{aligned}
$$

Lanjutkan sampai C7

Hasilnya dari Normalisasi Matrix $\mathrm{X}$ diperoleh matrix $X_{i j}$ yang dilihat dibawah ini.

$X_{i j}=\left[\begin{array}{lllllll}0,1644 & 0,3313 & 0,2132 & 0,2917 & 0,3592 & 0,2604 & 0,3114 \\ 0,1644 & 0,3313 & 0,3198 & 0,2917 & 0,3592 & 0,3906 & 0,3114 \\ 0,1644 & 0,3313 & 0,2132 & 0,2917 & 0,3592 & 0,2604 & 0,3114 \\ 0,4932 & 0,3313 & 0,4264 & 0,1459 & 0,1796 & 0,3906 & 0,3892 \\ 0,1644 & 0,2209 & 0,2132 & 0,4376 & 0,3592 & 0,1302 & 0,2335 \\ 0,1644 & 0,3313 & 0,3198 & 0,2917 & 0,1796 & 0,3906 & 0,3114 \\ 0,3288 & 0,2209 & 0,1066 & 0,4376 & 0,3592 & 0,1302 & 0,0778 \\ 0,4932 & 0,3313 & 0,4264 & 0,2917 & 0,1796 & 0,3906 & 0,3892 \\ 0,4932 & 0,4417 & 0,4264 & 0,2917 & 0,3592 & 0,3906 & 0,3892 \\ 0,1644 & 0,2209 & 0,3198 & 0,2917 & 0,3592 & 0,2604 & 0,3114\end{array}\right]$

3. Langkah selanjutnya yaitu menghitung nilai optimasi.

Perhitungan nilai optimasi untuk alternatif 1 :

$$
\begin{aligned}
& ((0,1644 * 0,18)+(0,3313 * 0,05)+ \\
& y_{1}=\begin{array}{l}
(0,2132 * 0,15)+(0,2917 * 0,2)+ \\
(0,3592 * 0,12)+(0,2604 * 0,16))-
\end{array} \\
& (0,3114 * 0,14) \\
& (0,0296+0,0166+0,0320+ \\
& \left.y_{1}=0,0583+0,0431+0,0417\right)-(0,0436) \\
& y_{1}=0,2212-0,0436 \\
& y_{1}=0,1777
\end{aligned}
$$

Berikut ini adalah hasil nilai optimasi dalam Tabel 11 berikut.

Tabel 11 Nilai Yi

\begin{tabular}{|l|l|l|}
\hline Alternatif & Nama Siswa & Y = Max -Min \\
\hline A1 & AR & 0,1777 \\
\hline A2 & Sas & 0,2145 \\
\hline A3 & AH & 0,1777 \\
\hline A4 & IR & 0,2282 \\
\hline A5 & MY & 0,1913 \\
\hline A6 & DP & 0,193 \\
\hline A7 & RA & 0,2267 \\
\hline A8 & AU & 0,2573 \\
\hline A9 & MM & 0,2843 \\
\hline A10 & MR & 0,1881 \\
\hline
\end{tabular}

Dari hasil diatas, dapat dilihat rangking setiap alternatif dari perhitungan kriteria terhadap siswa/i pada Tabel 12 berikut.

Tabel 12 Hasil Rangking

\begin{tabular}{|l|l|l|l|}
\hline Alternatif & Nama Siswa & Nilai Yi & Rangking \\
\hline A9 & MM & 0,2843 & 1 \\
\hline A8 & AU & 0,2573 & 2 \\
\hline A4 & IR & 0,2282 & 3 \\
\hline A7 & RA & 0,2267 & 4 \\
\hline A2 & Sas & 0,2145 & 5 \\
\hline A6 & DP & 0,193 & 6 \\
\hline
\end{tabular}




\begin{tabular}{|l|l|l|l|}
\hline Alternatif & Nama Siswa & Nilai Yi & Rangking \\
\hline A5 & MY & 0,1913 & 7 \\
\hline A10 & MR & 0,1881 & 8 \\
\hline A1 & AH & 0,1777 & 9 \\
\hline A3 & AR & 0,1777 & 10 \\
\hline
\end{tabular}

Dari hasil perhitungan menggunakan metode MOORA dari 10 alternatif maka yang berhak mendapatkan bantuan PIP dengan nilai tertinggi yaitu A9 yaitu MM dengan nilai 0,2843.

Pada penelitian ini sistem dibangun menggunakan bahasa pemrograman PHP dengan basis data MySQL, aplikasi sistem pendukung tersebut adalah sebagai berikut:

1. Tampilan Halaman Login

Setelah sistem dijalankan maka akan tampil halaman login. Halaman ini adalah halaman awal untuk admin dan digunakan untuk melakukan login sebagai pintu masuk ke halaman menu utama sistem. Seorang admin harus memiliki username dan password. Berikut ini merupakan desain tampilan interface halaman login yang dirancang oleh penulis:

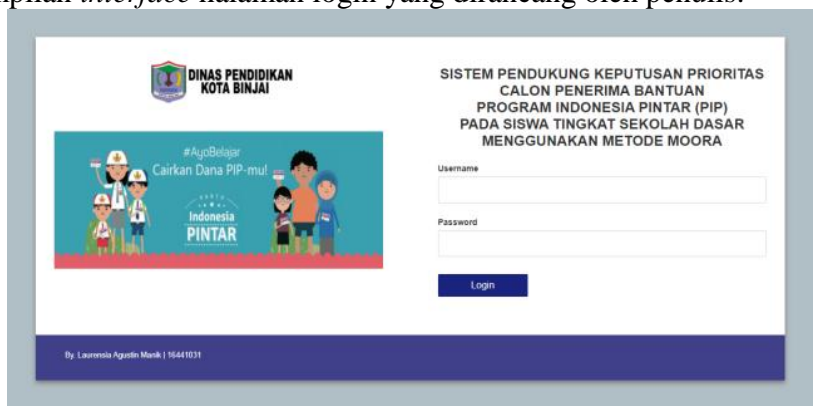

Gambar 1. Tampilan Halaman Login

2. Tampilan Halaman Beranda

Halaman beranda adalah tampilan awal saat admin masuk setelah halaman login. Tampilan dari halaman beranda adalah sebagai berikut:

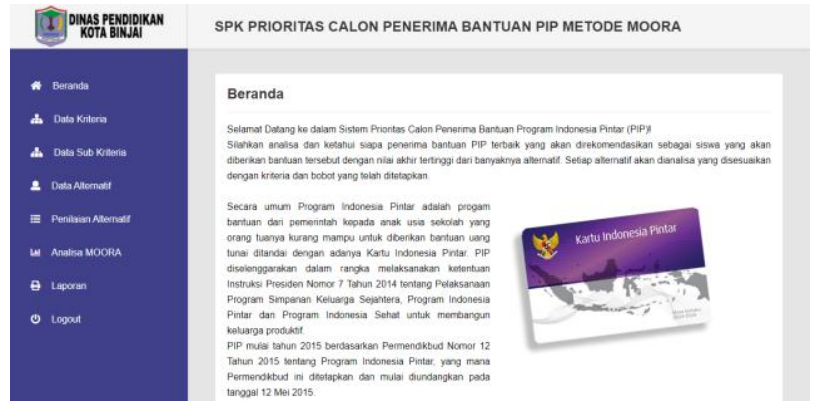

Gambar 2. Tampilan Halaman Beranda

3. Tampilan Halaman Data Kriteria

Pada tampilan halaman data kriteria, admin dapat menginput banyaknya kriteria yang diperlukan. Selain melakukan input data kriteria, admin juga dapat melihat data yang sudah di input serta dapat melakukan edit data dan jika ada kesalahan dapat melakukan hapus data. Tampilan dari halaman input kriteria adalah sebagai berikut:

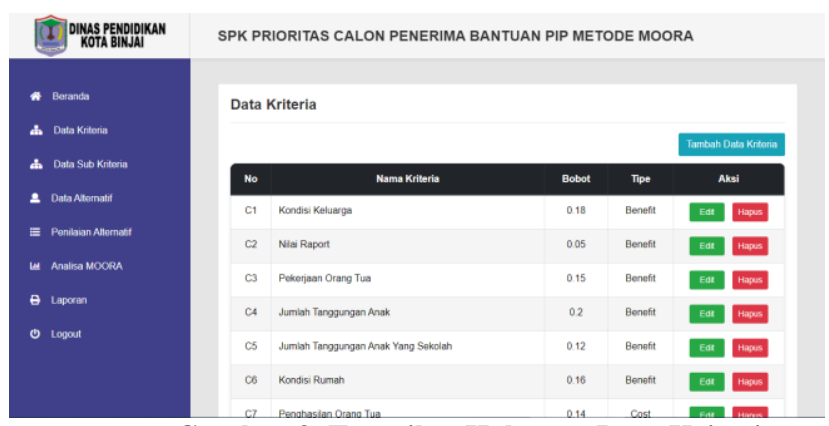

4. Tampilan Halaman Data Sub Kriteria

Gambar 3. Tampilan Halaman Data Kriteria

Pada tampilan halaman data sub kriteria, admin dapat melakukan penambahan penilaian kriteria berdasarkan kriteria yang ada. Tampilan dari halaman input sub kriteria adalah sebagai berikut:

Sistem Pendukung Keputusan Prioritas Calon Penerima Bantuan Program Indonesia Pintar (PIP) pada Siswa Tingkat 


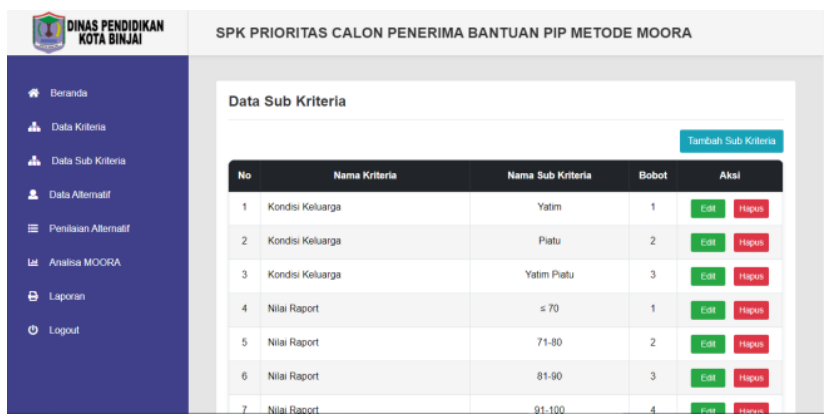

Gambar 4. Tampilan Halaman Data Sub Kriteria

5. Tampilan Halaman Data Alternatif

Pada tampilan halaman data alternatif, admin dapat menginput data nama calon penerima bantuan PIP yang menjadi alternatif. Selain melakukan input data alternatif, admin juga dapat melihat data yang sudah di input serta dapat melakukan edit data dan jika ada kesalahan dapat melakukan hapus data. Tampilan dari halaman input alternatif adalah sebagai berikut:

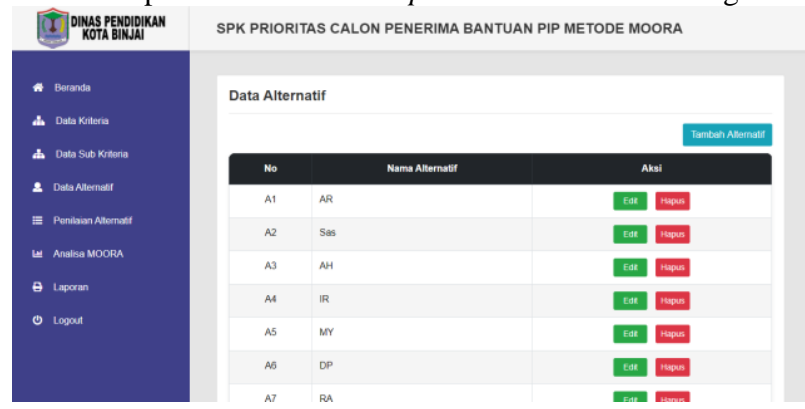

Gambar 6. Tampilan Halaman Data Alternatif

6. Tampilan Halaman Penilaian Alternatif

Halaman ini merupakan halaman saat admin melakukan penilaian alternatif berdasarkan kriteria yang ada. Tampilan dari halaman penilaian alternatif adalah sebagai berikut:

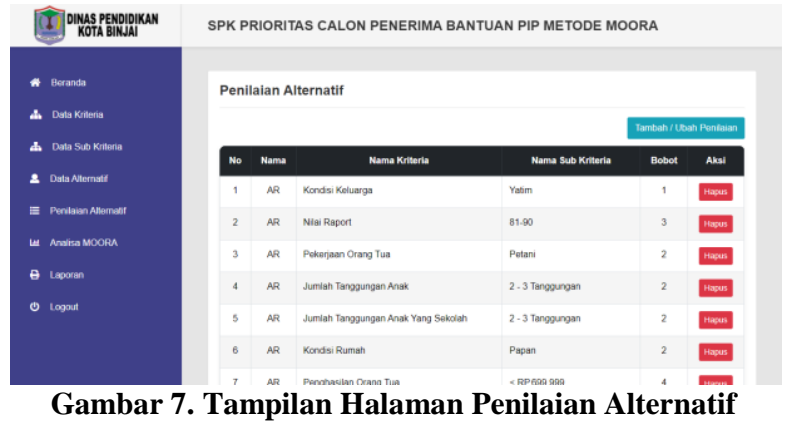

7. Tampilan Halaman Analisa Metode MOORA

Pada halaman ini admin dapat melihat analisa dari metode MOORA serta hasil akhir dan grafik hasil. Tampilan dari halaman analisa MOORA adalah sebagai berikut:

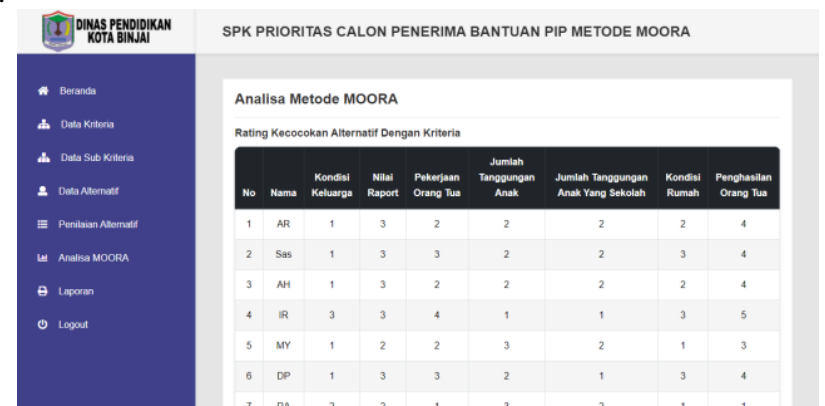

Gambar 8. Tampilan Analisa Metode MOORA

KESIMPULAN

Berdasarkan hasil analisa yang telah dilakukan oleh penilis, maka dapat menjadi kesimpulan sebagai berikut: 
1. Sistem pendukung keputusan dapat diterapkan untuk prioritas calon penerima bantuan Program Indonesia Pintar (PIP), sehingga dapat membantu pihak kantor Dinas Pendidikan dalam mengambil keputusan prioritas calon penerima bantuan PIP agar tepat sasaran.

2. Berdasarkan hasil perhitungan menggunakan metode Multi-Objective Optimization on the basis of Ratio Analysis (MOORA) terdapat nilai tertinggi yaitu pada Alternatif ke-9 (A9) yaitu atas nama MM dengan nilai 0,2843 sebagai alternatif terbaik dan direkomendasikan untuk diberikannya bantuan PIP dan nilai terendah yaitu pada Alternatif ke-3 (A3) yaitu atas nama AH dan Alternatif ke-1 (A1) atas nama AR dengan nilai yang sama yaitu 0,1777.

\section{DAFTAR PUSTAKA}

[1] "Dinas Pendidikan | Kota Binjai - Sumatera Utara.” http://binjai.siap.web.id/ (accessed Mar. 26, 2021).

[2] "Badan Pusat Statistik Kota Binjai." https://binjaikota.bps.go.id/istilah/index.html?Istilah_page=5 (accessed Mar. 26, 2021).

[3] T. Limbong et al., Sistem Pendukung Keputusan: Metode \& Implementasi. Yayasan Kita Menulis, 2020.

[4] T. Limbong, J. Simarmata, M. Rofendi Manalu, A. Rikki, and D. M. Rajagukguk, "Implementation of Multi Factor Evaluation Process (MFEP) in Assessment of Employee Performance Achievement," J. Phys. Conf. Ser., vol. 1573, no. 1, 2020, doi: 10.1088/1742-6596/1573/1/012022.

[5] Kusrini, Konsep dan Aplikasi Sistem Pendukung Keputusan. 2007.

[6] H. Retnaningsih, "Program Indonesia Pintar: Implementasi Kebijakan Jaminan Sosial Bidang Pendidikan (Studi di Kota Kupang, Provinsi Nusa Tenggara Timur dan Kota Palembang, Provinsi Sumatera Selatan),” J. Aspir., vol. 8, no. 2, pp. 161$177,2017$.

[7] R. Hendro Agung and B. S. Ginting, "PENERAPAN METODE MULTI-OBJECTIVE OPTIMIZATION ON THE BASIS OF RATIO ANALYSIS (MOORA) DALAM SISTEM PENDUKUNG KEPUTUSAN PENENTUAN KADAR MINYAK MENTAH,” J. Inform. Kaputama(JIK), vol. 4, no. 1, pp. 9-19, Jan. 2020, Accessed: Mar. 26, 2021. [Online]. Available: https://jurnal.kaputama.ac.id/index.php/JIK/article/view/223.

[8] T. Limbong et al., "The Implementation of Multi-Objective Optimization on the Basis of Ratio Analysis Method to Select the Lecturer Assistant Working at Computer Laboratorium," 2018.

[9] A. Kusuma, A. Nasution, R. Safarti, R. K. Hondro, and E. Buulolo, "Sistem Pendukung Keputusan Pemilihan Siswa / I Teladan Dengan Menggunakan Metode Multi-Objective Optimization on The Basis of Ratio Analisis ( MOORA )," Sist. Pendukung Keputusan Pemilihan Siswa / I Teladan Dengan Menggunakan Metod. Multi-Objective Optim. Basis Ratio Anal. (MOORA ), vol. 5, no. 2, pp. 114-119, 2018. 